\title{
726-P: Glucose Control Using Fast- Acting Insulin Aspart in a Real-World Setting: A One-Year Multicenter Study in People with Type 1 Diabetes Using Continuous Glucose Monitoring
}

LISA BILLION, SARA CHARLEER, LAURENS VERBRAEKEN, MIRA STERCKX, KATO VANGELABBEEK, NATHALIE DE BLOCK, CHARLIEN JANSSEN, NANCY BOLSENS, EVELINE L. DIRINCK, FRIDA W. PEIFFER, KRISTOF P. VAN DESSEL, CHANTAL MATHIEU, PIETER GILLARD, CHRISTOPHE DE BLOCK

Diabetes 2021;70(Supplement_1):726-P

https://doi.org/10.2337/db21-726-P

Objective: Data on switching from traditional mealtime insulin analogs to fast-acting insulin aspart (Fiasp) in routine clinical practice are sparse. The aim was to evaluate the efficacy and safety of this switch in a "real-world" clinical practice setting in adult people with type 1 diabetes (PWD1) who were using intermittent or real-time continuous glucose monitoring (iCGM or rtCGM) in Belgium.

Research Design and Methods: Data from 438 adult PWD1 (60\% men, age 44.6 $\pm 16.1 \mathrm{y}$, duration of diabetes $21.5 \pm 14.0 \mathrm{y}$, iCGM/rtCGM: $391 / 47$, multiple daily injections/pump: 409/29), who initiated Fiasp between January 2018 and May 2020 were retrospectively analyzed. The primary endpoint was the evolution of time in range (TIR, 70-180 mg/dl) at $6(n=416)$ and 12 months $(n=380)$. Secondary endpoints included change in $\mathrm{HbA1c}, \mathrm{BMI}$, insulin doses, time below range $(\mathrm{T}<70$ and $\mathrm{T}<54 \mathrm{mg} / \mathrm{dl})$ and time above range ( $\mathrm{T}>180$ and $\mathrm{T}>250 \mathrm{mg} / \mathrm{dl})$.

Results: TIR improved from $50.3 \pm 15.6 \%$ to $54.3 \pm 15.1 \%$ at 6 months and $55.5 \pm 15.2 \%$ at 12 months $(p<0.0001)$, corresponding to an increase of 75 minutes/day at 12 months. $\mathrm{T}<70 \mathrm{mg} / \mathrm{dl}$ evolved from $7.4 \pm 5.5 \%$ to $7.6 \pm 5.8 \%$ and to $6.8 \pm 5.5 \%(\mathrm{p}=0.037)$, and $\mathrm{T}<54 \mathrm{mg} / \mathrm{dl}$ evolved from $3.1 \pm 3.3 \%$ to $3.1 \pm 3.7 \%$ and $2.5 \pm 3.0 \%(p=0.003)$ at 6 and 12 months, respectively. Also, $\mathrm{T}>180 \mathrm{mg} / \mathrm{dl}$ decreased from $42.3 \pm 16.7 \%$ to $38.1 \pm 16.5 \%$ and to $37.7 \pm 16.9 \%(p<0.0001)$, and $\mathrm{T}>250 \mathrm{mg} / \mathrm{dl}$ evolved from $16.5 \pm 12.8 \%$ to $13.8 \pm 11.8 \%$ and to $13.1 \pm 12.5 \%(p<0.0001)$ at 6 and 12 months. At 12 months $\mathrm{HbA1c}$ (from $7.8 \pm 1.1 \%$ to $7.7 \pm 1.0 \%$ ), insulin doses $(0.66 \pm 0.24$ to $0.62 \pm 0.21$ units $/ \mathrm{kg}$ body weight/day and ratio bolus/basal from 1.28 to 1.30) and BMI (from $25.8 \pm 4.0$ to $26.2 \pm 4.1 \mathrm{~kg} / \mathrm{m}^{2}$ ) did not change significantly.

Conclusions: In a Belgian real-world setting of adult PWD1, switching to Fiasp resulted in a $5 \%$ increased TIR, corresponding to $75 \mathrm{~min} /$ day, in combination with less time spent below and above range.

\section{Disclosure}

L. Billion: None. F. W. Peiffer: None. K. P. Van dessel: None. C.

Mathieu: Advisory Panel; Self; Novo Nordisk, Sanofi, Merck Sharp and Dohme Ltd., 
Eli Lilly and Company, Novartis, AstraZeneca, Boehringer Ingelheim, Roche, Medtronic, ActoBio Therapeutics, Pfizer, Insulet and Zealand Pharma, Research Support; Self; Medtronic, Novo Nordisk, Sanofi and ActoBio Therapeutics, Speaker's Bureau; Self; Novo Nordisk, Sanofi, Eli Lilly and Company, Boehringer Ingelheim, AstraZeneca and Novartis. P. Gillard: None. C. De block: Advisory Panel; Self; A. Menarini Diagnostics, Abbott Diagnostics, AstraZeneca, Boehringer Ingelheim, Eli Lilly and Company, MSD, Novartis AG, Novo Nordisk, Roche Diagnostics, Sanofi, Research Support; Self; AstraZeneca, Novo Nordisk, Speaker's Bureau; Self; A. Menarini Diagnostics, Abbott Diagnostics, Boehringer Ingelheim , Eli Lilly and Company, Novo Nordisk, Sanofi. S. Charleer: None. L. Verbraeken: None. M. Sterckx: None. K. Vangelabbeek: None. N. De block: None. C. Janssen: None. N. Bolsens: Advisory Panel; Self; Medtronic. E. L. Dirinck: None. 